\title{
A caixa de jóias: os papéis de Lúcio Cardoso
}

Adriana Saldanha Guimaräes

Pontifícia Universidade Católica do Rio de Janeiro

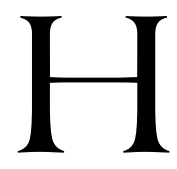

á pouco tempo, a literatura só era vista a partir do que era produzido e registrado em livro ou periódico. Hoje, a noção de obra não se limita mais aos livros publicados, abrange outros textos do autor. Ou seja, trabalha-se também com rascunhos, textos incompletos e outros "papéis", que por algum motivo não saíram da "caixa de jóias". Através da leitura desses documentos podemos elucidar um pouco mais os caminhos percorridos, não só pelo escritor como também pela história da literatura brasileira. Lúcio Cardoso, em seu acervo, nos deixou algumas preciosidades e algumas pistas de suas obras literárias.

A intenção da pesquisa em arquivos é percorrer os caminhos, os já percorridos e outros possíveis. Trabalhar com documentos que, por muito tempo, não foram considerados importantes para a literatura.

O documento, segundo Foucault, é um objeto de trabalho arqueológico, um "monumento" que é para ser desmontado, para ser analisado. O olhar arqueológico é rastreador, de detetive. $\mathrm{O}$ pesquisador diante de um arquivo recorta, desmonta, revê as diversas facetas e deixa a sua marca. Vale dizer que não existem verdades, apenas interpretações. Foucault legitima os recortes diante da impossibilidade de se falar de tudo.

Ao reler Lúcio, o interessante foi notar como a produção intelectual deste escritor segue os mesmos temas. Muitas vezes tive a impressão que as histórias se repetiam, pois as angústias dos personagens são quase sempre as mesmas. Essas mesmas questôes, angústias e segmentos são também pautados em seus diários.

A obra de Lúcio Cardoso é como uma grande teia, seus romances, novelas e até o Diário, fazem parte de um mesmo conjunto. Um dos temas que mais me chamou atenção foi o da morte. Lúcio Cardoso, a todo tempo, como uma obsessão, refere-se à morte, em todos os seus escritos. Em seus 
romances, faz sempre uma menção a este tema, chega mesmo a reservar alguns capítulos para a descrição da morte. No seu último romance, inacabado, $O$ viajante, Lúcio Cardoso criou um personagem que era fazedor de caixões. Em seu Diário, a obsessão pela morte é bem marcante.

"O que é a morte senão a essência de todos nós?" Lúcio tinha uma verdadeira obsessão por este tema. A sombra da morte está sempre presente. Faz parte da agonia de viver. "A morte não é só o falecer das criaturas; sua realidade é mais forte ainda no mundo". ${ }^{1}$ Fala-se também da possibilidade da morte como continuidade, fazendo parte de um processo: "Tudo que elas destroem pode muito bem ser destruído; o que acaba é apenas o mundo já morto. Resta tanta coisa ainda. Parece até que houve uma multiplicação". ${ }^{2}$ A vida é feita de pequenas mortes e a cada morte somos sempre outros, "a fim de podermos atingir em verdade a morte que nos vive". ${ }^{3}$ Lúcio, tão envolvido em suas reflexões, cria uma imagem poética: "desde há muito a morte se acha instalada dentro de nós (...) - e a morte que nos espera, é a mesma que nos acompanha, como a sombra estrangeira que divisamos na limpidez dos muros". ${ }^{4}$ Diante dessa vida trágica onde a morte "é sutil e gosta de devorar silenciosamente as almas", 5 o poeta exclama: "Ó Morte / Supremo fruto para que se abrem as flores da nossa vida."

A escritura existe em conseqüência do pensamento da morte. O que nos persegue a vida como uma sombra, até que um dia se instala dentro de nós para sempre. Escreve-se para não morrer, ou seja, mesmo sendo o corpo finito, o que se escreve permanece. $\mathrm{O}$ desejo de escrever está relacionado ao mesmo desejo de arquivar. Escrever ou arquivar é um modo de escapulir da tensão que produz a questão da morte: tanto um quanto outro são produzidos pela reação à pulsão da morte. $\mathrm{O}$ mesmo pode-se dizer da vida.

Lúcio, durante muito tempo, paralelamente à produção de sua ficção, registrou, idéias e lembranças. Foi dos poucos escritores brasileiros a compor

${ }^{1}$ CARDOSO, 1942-1947, p. 148.

${ }^{2}$ CARDOSO, 1942-1947, p. 85.

${ }^{3}$ CARDOSO, s/d. [1960], p. 90.

${ }^{4}$ CARDOSO, s/d. [1960], p. 28-29.

${ }^{5}$ CARDOSO, 1971, p. 339.

${ }^{6}$ CARDOSO, 1941, p. 71. 
aquilo que chamou de "diário não-íntimo". ${ }^{7}$ Considerava-o parte de sua obra. Não fazia diferença entre a forma do diário e a de seus romances. Compõe o diário ao mesmo tempo em que compóe seus romances. Uma busca incessante dos mistérios da vida e da morte. Fazendo conjunto com sua obra, há uma parte do diário publicada, referente aos anos de 1949 a 1962 . A primeira parte, embora não traga data, foi publicada em 1960 e uma edição mais completa saiu em 1970.

No acervo de Lúcio, encontramos outros manuscritos relacionados à "escritura de diário": "Diário de terror", "Livro de bordo", e também anotações datilografadas, referentes ao período de 1942 a 1947, que parecem estar organizadas para publicação. Junto a estes fragmentos há uma nota introdutória datada de 1957, na qual o escritor reafirma a intenção de publicar esta parte do diário, "quando essas anotações foram primeiro tomadas, havia a intenção firme de uma publicação posterior integral e sem qualquer retoque na sua redação instantânea, quase sempre propositadamente bárbara". O tempo passou e ele mesmo percebeu ser insustentável a sua idéia de início: "as anotações eram desnecessariamente volumosas, e muitas vezes - quer por deliberada selvageria, quer por inépcia - tão mal escritas que seria simplesmente estupidez publicá-las assim”. Era preciso fazer uma revisão, reduzir o volume, repensar as idéias que não se sustentavam mais.

O que surpreende é o fato de Lúcio ter organizado essas anotações incluindo até mesmo uma nota introdutória e nunca tê-las publicado. A própria nota, ao mesmo tempo em que prepara esta parte para uma futura publicação, nega a viabilidade da mesma, uma vez que revela ser impossível publicar sem alterar o estilo e as idéias originais. Muito distante do que pretendia Lúcio num primeiro momento, manter propositadamente o material bruto de suas anotações. Será que foi por este motivo que Lúcio abandonou a intenção de publicá-las? Ou por esperar encontrar o editor ideal? Lúcio dedica esta parte do diário: "Aos homens de boa vontade". É possível fazer uma leitura de que Lúcio almejava um editor que fosse capaz de ler os fragmentos sem criticar ou alterar o estilo, mantendo o material na forma em que se encontrava. Provavelmente, o editor que Lúcio desejou não existia. Hoje, a dedicatória ainda se referindo à procura de um editor poderia

${ }^{7}$ CARDOSO, 1970, p. 215. 
ganhar um novo sentido. $\mathrm{O}$ da expectativa de um pesquisador que respeite, valorize e conserve o material exposto no arquivo.

No diário, Lúcio expõe suas idéias sobre esta forma de escritura de mim, ou seja, fala-se um pouco de si, do mundo, do escritor, das leituras, da literatura, do cinema, do teatro, do diário, da carta, dos beijos, do vazio da alma, da paisagem, das saudades... A escritura, feita de fragmentos que se assemelham a peças de quebra cabeça, constrói a identidade do escritor. Mas quem era Lúcio?

Lúcio provavelmente não queria ser como todo mundo, mas ao mesmo tempo mostrava-se insatisfeito com a sua inadaptação e tentava compreender a linguagem dos seus contemporâneos. Em sua escritura, seja por palavras ou imagens, aparece sua luta para compreender o mundo que o rodeia. A busca sempre infinita e a verdade nunca alcançada. Preferia viver no mundo da desordem, para ele, um equivalente de sua própria paisagem, pois não suportava as idéias estratificadas pelo senso comum. "Para mim não tem valor as teorias estáticas, os ideais paralisados: o que me toca são os movimentos da dinâmica e da propulsão, ainda que a meta seja o infinito, e o horizonte por descobrir o nada". ${ }^{8}$ Usava os questionamentos de vida como temática para sua literatura. Só dessa maneira é que Lúcio conseguia reconhecer a sua realidade. A realidade é múltipla, tanto quanto a linguagem que a constrói. “(...) - e assim sendo, todo cheio de vozes que só sabem se exprimir através das vias brancas do papel, só consigo vislumbrar a minha realidade através da informe projeção deste mundo confuso que me habita".

Lúcio escreve para ouvir sua própria voz, misturando ficção e memória, fazendo da obra uma literatura mais intimista. Este escrever para a vida:

Se quisesse, poderia viver sem escrever, o que não seria nada de mais. Mas acho mais divertido escrever: resolvo até fazer obras, forçando coisa por coisa, imaginando página por página, sendo artificial ou 'sincero' numa grande confusão. Escrever é bom para sentir e o que quero é sentir. Há também uma outra vontade que escrever pode ajudar: a de crescimento contínuo. ${ }^{10}$

\footnotetext{
${ }^{8}$ CARDOSO, nov. 1961.

${ }^{9}$ CARDOSO, s/d. [1960], p. 104.

${ }^{10}$ CARDOSO, 1942-1947, p. 77.
} 
O escrever é a alma em conflito: pode ser canto e choro, artificial e sincero. Uma vez declarou apreciar só os autores que escreviam com a alma, "mesmo sem gênio, só me interessam as obras em que os autores puseram toda a sua alma". ${ }^{11}$ Ora, Lúcio só concebia o romance dessa maneira:

Mas tendo afirmado que acredito no romance, quero acrescentar que acredito apenas naquele que é feito com sangue, e não com o cérebro unicamente ou o caderninho de notas, no que foi criado com as vísceras, os ossos, o corpo inteiro, o desespero e a alma doente do seu autor, do que foi feito como se escarra sangue contra a vontade e como quem lança à face dos homens uma blasfêmia. ${ }^{12}$

A sua estética romanesca rompe o sistema convencional de representação. O que é belo deve ser posto em questão.

Tudo o que é belo só deve ser útil para fazer crescer nossa impressão de intranqüilidade. A beleza é o supremo espasmo, a angústia máxima, o sentimento maior de furor ante a fragilidade e a possibilidade de destruição de tudo. E é assim, sob o terror, que o homem se realiza integralmente. Estamos nus, integrais em toda estranheza de nosso trágico destino, quando sentimos o chão faltar sob nossos pés. ${ }^{13}$

Tudo que é belo tem seu lado perverso. Sua obra é feita das "águas puras" quanto das "impuras". "Não se amassa o barro apenas com águas puras, mas com tudo o que a correnteza traz, limos e detritos. Isto é o que transforma o liquido comum em húmus, e garante no final a solidez das construçóes". ${ }^{14}$ Lúcio desejou o feio para despertar o mistério, a surpresa, o novo encanto. Como Baudelaire, o poeta da modernidade, que foi capaz de pressentir que todo horror tem seu encanto.

Não encontrar a palavra exata faz parte do "mal da escrita". Escreve para não cair no vazio e o vazio é a própria escrita, que não abarca todos os pensamentos. A escritura acontece na tentativa de encontrar e se apoderar

\footnotetext{
${ }^{11}$ CARDOSO. Arte pela Arte, S.I.

${ }^{12}$ CARDOSO, 1991, p. 762.

${ }^{13}$ CARDOSO, 1970, p. 27.

${ }^{14}$ CARDOSO, 1961, p. 74.
} 
de todos os instantes. "Quando se quer ir muito longe no pensamento ficase impossibilitado de escrever". ${ }^{15}$ Talvez por ter ido muito longe no pensamento, Lúcio tenha tido dificuldades em prosseguir um de seus romances: "Continuo a escrever 'O Viajante', mas sem encontrar a forma adequada à história. Além do mais o estilo é arrastado, não vive e nem explode como eu desejaria". ${ }^{16}$ Este mesmo tema foi repetido inúmeras vezes em seu Diário completo. No fim, descobre ser O Viajante, esta obra inacabada, "a essência do mal, em permanente trânsito...". ${ }^{17}$ A mesma essência que tinha a sua vida.

A vontade de expressar seu pensamento e a impossibilidade de mostrá-lo somente pela escrita fez com que Lúcio procurasse outras linguagens, no cinema com as imagens e no teatro com os gestos. No fim de sua vida procura na pintura o que não teria conseguido expressar com a sua escrita.

Passou a transportar para as telas, com a mão esquerda (que, no entanto, era incapaz de escrever, só de pintar) transparências e luzes e levezas que antes ele não parecia ter conhecido e ter sido iluminado por elas: tenho um quadro, de antes da doença, que é quase totalmente negro. A luz lhe viera depois das trevas da doença. ${ }^{18}$

Em vida, muitas vezes, a palavra silenciava. No dia 6 de junho de 1944, em plena Segunda Guerra, Lúcio registra em seu diário:"Recebi a notícia de manhã, de meu pai, quando, em meu quarto, já me preparava para escrever algo nesse diário. Senti surpresa apesar de saber da iminência da coisa. Senti um choque diferente dos que experimento. Pensando então em mim e nos homens participando da maior operação da guerra: a letra é morta”. ${ }^{19}$ Este pensamento não era para condenar sua vida como escritor nem mesmo se tivesse de fazer parte desta operação, mas apresenta-se, "como simples compreensão do que o que está se passando lá é um abismo de vida mesmo, apesar de tanta morte". ${ }^{20}$ Mas quanto tempo duraria este silêncio?

\footnotetext{
${ }^{15}$ CARDOSO, 1942-1947.

${ }^{16}$ CARDOSO, 1970, p. 175.

${ }^{17}$ CARDOSO, 1970, p. 290.

${ }^{18}$ LISPECTOR, 30 jun. 1973.

${ }^{19}$ CARDOSO, 1942-1947.

${ }^{20}$ CARDOSO, 1942-1947.
} 
A vida, como a escritura, é um jogo cujas peças podem estar sempre variando. As diversas possibilidades é que enriquecem o jogo. Qualquer jogo, assim como qualquer escritura, supóe rupturas.

Em seu diário publicado, Lúcio Cardoso relata inúmeras vezes o que leva a escrever um diário. Em agosto de 1949, ele fala dos papéis perdidos:

Seria difícil dizer qual o motivo real que me leva a escrever este Diário, depois de ter perdido um que redigi durante vários anos (lembro-me que, naquela época, senti os meus dezoito anos emergirem a uma insondável distância de mim, enquanto eu experimentava, porque não confessar, uma inequívoca sensação de alívio, como quem tivesse atirado ao mar uma inútil a fastidiosa bagagem...) e de ter tentado outros que nunca levei adiante. Creio que é simplesmente o fato de sentir que começo a viver experiências importantes (quando a idade nos chega e principiamos a envelhecer, quase todas as experiências são importantes, como se selecionássemos de antemão a qualidade dos fatos, que vão compor a trama de nosso destino) e que talvez um dia alguém se interesse pelo roteiro destas emoções já mortas. Para mim mesmo, para meu deleite íntimo, confesso que jamais tentaria salvar estes fragmentos do passado: aos meus olhos, não possuem nenhum interesse. E depois, tudo o que morre é porque já teve o seu tempo. Mas insensivelmente penso nos outros, nos amigos que nunca tive, naqueles a quem eu gostaria de contar estas coisas como quem faz confidências no fundo de um bar. Esse diabólico e raro prazer de confidência, que vai se desfazendo à medida que perdemos a confiança na amizade, que ela mais a mais se afasta de nós como um bem inacessível... Sim, esse gosto de confidência que tanto nos persegue, e que em muitos escritores, é como a própria suma de suas inspirações e pensamentos. E finalmente, quem sabe, apenas esse prazer de rabiscar, que é de todos nós, e nos faz comprar cadernos inúteis e apontar lápis que nunca usaremos. Fora destas pálidas razōes, nada vejo que possa alegar a favor da elaboração deste Diário - e, é preciso dizer, que não tenho a menor veleidade de traçar aqui um itinerário espiritual ou realizar um inventário de idéias para servir aos outros. Nada quis e nada quero: escrevo apenas porque o sol é bom e porque me sinto desamparado nesta enorme manhã de pureza e euforia. ${ }^{21}$

${ }^{21}$ CARDOSO, s/d. [1960], p. 13-14. 
Em agosto de 1958, Lúcio continua repensando a questão do diário: Às vezes eu me pergunto qual a vantagem de se manter um Diário destes. Para salvar o que? Sensaçōes? Pensamentos? E a que futuro chegarão um dia essas notas, sob que olhos tombarão, frios e desinteressados, que não arrancarão da minha frase acima, por exemplo, nada, nem um pouco dessa experiência que vivi, deste sol, desta paz, deste dia, precisamente deste a que me refiro, e que ainda aqui está, com sua calma, com sua luz, que só reviverão para mim, numa outra época, num outro instante em que abrir este caderno... Sim, jamais o verão, jamais terão dele a ciência exata que eu tenho: mas se um dia alguém achar em seu caminho um outro momento assim, saberá a que me refiro e o que quero - e entenderá a calma e o sol deste momento, porque para isto são feitos os diários, e o entendimento de suas sensações furtivas e precárias. ${ }^{22}$

Nas últimas páginas de seu Diário, Lúcio escuta a voz de Cornélio Penna, "o seu sofrimento é um sofrimento bom, de permanecer à margem". E Lúcio responde:

Não há, Cornélio pior sofrimento do que permanecer à margem. Não tenho temperamento para isto. Quero amar, viajar, esquecer - quero terrivelmente a vida, porque não creio que exista nada nem de mais belo e nem de mais terrível do que a vida. E aqui estou: tudo o que amo não me ouve mais, e eu passo com a minha lenda, forte sem o ser, príncipe, mas esfarrapado. ${ }^{23}$

O pesquisador faz como o leitor da Crônica da casa assassinada: reconstitui os fragmentos de uma história esfacelada em documentos. O arquivo se constitui de fragmentos, justaposição de elementos heterogêneos. Isto é o que torna muito interessante a sua leitura no momento em que se encontram outros documentos que tratam da mesma temática. Num mesmo arquivo, podemos encontrar documentos produzidos independentemente um do outro, mas que dialogam entre si. O que contorna a cena muitas vezes revela preciosidades.

Em seu acervo encontrei uma folha datilografada em que Lúcio comentava a vontade de publicar seu Diário:

\footnotetext{
${ }^{22}$ CARDOSO, 1970, p. 261.

${ }^{23}$ CARDOSO, 1970, p. 304.
} 
Há muitos anos, desde que empunhei a pena pela primeira vez, que anoto impressóes sobre o que sinto e o que acontece comigo e em torno de mim. Nesses primeiros cadernos, vazados numa linguagem exaltada e romântica, o destino encarregou-se deles, pela mão de um ladrão que, supondo existirem jóias na caixa onde os guardava, deve ter tido o desprazer de só encontrar papéis - e papéis que não serviam para nada. Só a partir de 1949, quando aos poucos meti-me numa crise que ameaçou abalar toda a minha vida e meu destino de escritor, comecei a anotar com mais cuidado o que via e o que sentia, no mesmo esforço de quem se agarra a uma tábua de salvação para não naufragar. / (...) /. Alguns leitores fortuitos aconselharam-me a que não publicasse isto, tendo em vista a má fé geral com que se acolhe publicação desta espécie. Concordei, e retive os cadernos algum tempo em mãos. Não os retenho mais, exatamente porque me julgo longe da crise que me afetou. Estou longe demais, hoje em dia, para reter-me a esses escolhos que só representam um instante da minha vida.

Nada renego do que aqui disse, se bem que me ache hoje colocado num ponto diferente. Nada renego, e se lanço à publicidade essas pobres folhas, é que imagino que elas tenham sido escritas exatamente para serem publicadas, e não para testemunhar de uma experiência que devesse ficar comigo apenas.

(...)

Por enquanto, é com alegria que me lanço ao pasto: não consigo conter nem a fúria, nem o sentimento de poder que me leva a publicar estas páginas.

O escritor de diário quer ser lido. Penso na caixa onde guardavam os cadernos que os ladrões levaram, eles imaginavam ser jóias, mas eram só papéis. $\mathrm{Na}$ verdade, para nós leitores, os ladrões levaram a caixa de jóias, os papéis de Lúcio Cardoso.

Lendo as cartas, descobri uma de Murilo Mendes que elogiava o primeiro Diário de Lúcio:

(...) Cercado de trabalho e compromissos de encontros, não disponho de tempo para fazer uma análise do livro. Mando-lhe apenas duas palavras para dizer-lhe a forte impressão que o mesmo me deixou. É claro que não me revelou um escritor e um homem, que tenho gosto de conhecer desde tantos anos. Confirmou, entretanto, aos meus olhos, este escritor e este homem. Alguém que nada contra a corrente, um inconformista num mundo de maníacos da publicidade, de falsos artistas, de 
vendidos - Salvo naturalmente as exceçóes menos numerosas do que seria de desejar. O Diário é o documento de uma personalidade insubornável, humana e sincera ainda nas suas lacunas e fraquezas; alguém corajoso. Aguardo com interesse os volumes subseqüentes. (...).

Para finalizar este passeio pelos papéis de Lúcio, um olhar na pasta de jornais, descubro um curioso artigo de Jorge Amado intitulado "Página de diário sobre um diário", podemos voltar no tempo e redesenhar a cena do lançamento do Diário de Lúcio Cardoso numa livraria de Copacabana:

(...) Passo a noite, até a madrugada, lendo o primeiro volume do Diário de Lúcio Cardoso. E quando termino a leitura e consigo dormir, o livro não me abandona, sonho com ele, vejo Lúcio desesperado na praia, às voltas com câmeras de cinema e com seu drama interior. (...) Encontro Lúcio Cardoso, dias depois, numa livraria, em Copacabana, autografando o seu livro. A livraria está cheia, é uma espécie de triunfo, de consagração do escritor. Lúcio, sentado ante a mesa, assinando, parece-me um pouco perdido entre tanta gente, tanto ruído, tantos abraços. Como um náufrago envolto numa tempestade. Demoro-me um pouco a espiá-lo, ele não sabe direito o que fazer, é a negação de tudo isso, desse ruidoso lançamento. (...). E, de súbito, eu o vejo nos idos de 33 ou 34, um menino éramos todos, a publicar seu primeiro romance. "Maleita", que ainda há dois anos reli com tanta emoção. Vejo-o na Schmidt-editor, adolescente, a discutir comigo, cheio de sonhos e esperanças. Naquele tempo, literatura era assunto apenas de alguns, não havia tanta gente e tanto interesse em torno de livros e autores. Mas, vivíamos para literatura, ou seja, vivíamos para a vida de forma ardente e profunda. $\mathrm{O}$ romance de Lúcio abalou a crônica literária de então. Não houve quem não compreendesse de imediato estarmos diante de um grande um desses que constroem a literatura. $(. . .)^{24}$

Se quisermos, dar um outro passeio pelo seu acervo, juntarmos de novo as peças deste quebra cabeça, recortar, desmontar, com certeza, encontraremos outras relíquias deste príncipe esfarrapado que, ao construir sua literatura, acabou nos deixando uma verdadeira 'caixa de jóias', o acervo e sua obra, cheia de preciosidades.

${ }^{24}$ AMADO, 1960. 


\section{Referências Bibliográficas}

\section{I - Obras de Lúcio Cardoso}

CARDOSO, Lúcio. Maleita (1934). Rio de Janeiro: Presença, 1974.

. Salgueiro. Rio de Janeiro: José Olympio, 1935.

. A luz no subsolo (1936). Rio de Janeiro: Expressão e Cultura/INL, 1971.

. Mãos vazias. Rio de Janeiro: José Olympio, 1938.

. O desconhecido. Rio de Janeiro: José Olympio, 1940.

. Dias perdidos (1940). Rio de Janeiro: Nova Fronteira, 1980.

. Poesias. Rio de Janeiro: José Olympio, 1941.

. Novas poesias. Rio de Janeiro: José Olympio, 1944.

. Inácio (1944). Rio de Janeiro: Salamandra, 1984.

. A professora Hilda. Rio de Janeiro: José Olympio, 1946.

. Anfiteatro. Rio de Janeiro: Agir, 1946.

. O enfeitiçado. Rio de Janeiro: José Olympio, 1954.

. Crônica da casa assassinada (1959). Ed. crítica coord. por Mario Carelli. España, Archivos/CSIC, 1991. (Col. Archivos, 18).

. Confissões de um homem fora do tempo. In: CARDOSO, Lúcio.

Crônica da casa assassinada (1959). Ed. crítica coord. por Mario Carelli, España, Archivos/CSIC, 1991, p. 762-763. (Col. Archivos, 18).

. Diário I. Rio de Janeiro: Elos, s/d. [1960].

. Diário proibido - páginas secretas de um diário e de uma vida. Senhor, Rio de Janeiro, n. 33, p. 68-74, nov. 1961.

CARDOSO, Lúcio. Diário completo. Rio de Janeiro: José Olympio/INL, 1970. . O viajante (inacabado). Rio de Janeiro: José Olympio, 1973.

. Poemas inéditos. Apres. e ed. de Octávio de Faria. Rio de Janeiro, Nova Fronteira, 1982. 


\section{II - Arquivo Lúcio Cardoso do Arquivo-Museu de Literatura Brasileira da Fundação Casa de Rui Barbosa - ALC/AMLB/ FCRB}

CARDOSO, Lúcio. Diário de terror. S.I., s/d., 27 fls.

. Diário de bordo. S.I., s/d., 4 fls.

. Arte pela arte (artigo). S.I.

. Cadernos-diários e notas esparsas. "Diário" parte não publicada (19441947), 241 fls.

. Assuntos diversos. Diário da Tarde, Jornal do Brasil e outros (recortes: 1934-1961).

. Diário não-íntimo. A Noite, Rio de Janeiro, s/d. (Recortes).

Algumas correspondências de Clarice Lispector, Murilo Mendes, Otávio Faria, Cornélio Penna, Fernando Sabino, Paulo Mendes Campos, Mario de Andrade, Carlos Drummond de Andrade e Adonias Filho.

Recortes de jornais de vários autores sobre Lúcio Cardoso.

\section{III - Geral}

AMADO, Jorge. Página de diário sobre um diário. Leitura, Rio de Janeiro, n. 42, dez. 1960.

BAUDELAIRE, Charles. Escritos intimos. Lisboa: Stampa, 1982.

BLANCHOT, Maurice. A solidão essencial. In: O espaço literário. Rio de Janeiro: Rocco, 1987.

CARDOSO, Maria Helena. Por onde andou meu coração. 2. ed. Rio de Janeiro: José Olympio, 1968.

CARDOSO, Marília Rothier. De próprio punho - manuscritos de Lúcio Cardoso e Pedro Nava. Palavra, Rio de Janeiro: PUC, n. 4, p. 44-57, 1997.

CARELLI, Mário. Corcel de fogo: vida e obra de Lúcio Cardoso (1912-1968). Trad. Júlio Castañon Guimarães. Rio de Janeiro: Guanabara, 1988.

CURY, Maria Zilda Ferreira. Acervos: gênese de uma nova crítica. In: MIRANDA, Wander Melo (Org.). A trama do arquivo. Belo Horizonte: Editora UFMG, 1995. p. 53-65. 
DERRIDA, Jacques. Mal d'archive. Paris: Galillée. 1995. . L'écriture et la différence. Paris: Seuil, 1967.

ECO, Umberto. Obra aberta. São Paulo: Perspectiva. 1944. (Coleção Debates).

FOUCAULT, Michel. Arqueologia do saber. Rio de Janeiro: Vozes, 1972. . O que é um autor? Lisboa: Veja, s/d.

GUIMARÃES, Júlio Castanõn. Distribuição de papéis: Murilo Mendes escreve a Carlos Drummond de Andrade e a Lúcio Cardoso. Rio de Janeiro, FCRB/ MinC, 1996. (Papéis avulsos, 27).

GUSDORF, Georges. Les écritures du moi. Paris: Odile Jacob, 1991.

INVENTÁRIO do arquivo Lúcio Cardoso. RANGEL, Rosângela Florido; LEITÃO, Eliane Vasconcellos (Org.). Rio de Janeiro: FCRB/MinC, 1989. (Série AMBL, 4).

JOURNAL (le) intime et ses formes littéraires. Actes du Colloque de set. 1975, (Org. de V. Del Litto). Paris: Librairie Droz, 1978.

LISPECTOR, Clarice. Lúcio Cardoso. Correio do Povo, Porto Alegre, 30 jun. 1973, S.I.

SOUZA, Eneida Maria de. Vozes de Minas nos anos 40. In: MIRANDA, Wander Melo (Org.). A trama do arquivo. Belo Horizonte: Ed. UFMG, 1995, p. 29-45.

\section{Resumo}

Um passeio pelo acervo de Lúcio Cardoso identificando algumas relíquias e pistas de sua obra literária.

\section{Résumé}

Une promenade dans l'archive de Lúcio Cardoso en réperant quelques reliques et pistes de son oeuvre littéraire. 